\title{
Toll-like receptor-4 in human and mouse colonic epithelium is developmentally regulated: a possible role in necrotizing enterocolitis
}

\author{
Di Meng' ', Weishu Zhu', Hai Ning Shi', Lei Lu², Vasuki Wijendran', Winber Xu' and W. Allan Walker ${ }^{1}$
}

BACKGROUND: Necrotizing enterocolitis (NEC) is an immature intestinal condition resulting in devastating intestinal inflammation due to unknown mechanisms. Evidence has suggested that intestinal maturation attenuates the severity of NEC and Toll-like receptor 4 (TLR4) has been suggested to play a critical role in its pathogenesis. We investigated whether maturational effects of TLR4 expression in immature colon might contribute to the development of NEC.

METHODS: TLR4 colonocyte expression was detected by immunofluorescence confocal microscopy. Interleukin-6 (IL6) levels were assayed by an enzyme-linked immunosorbent assay (ELISA).

RESULTS: TLR4 expression was high in fetal colonic epithelium in human and mouse, with earlier gestation having a higher surface/cytoplasm distribution. TLR4 remained high in mouse postnatal day 1 but the surface/cytoplasm distribution was reduced. TLR4 decreased in amount and then was expressed in crypts in the mature human and mouse colon. Hydrocortisone (HC) reduced the surface/cytoplasm distribution of TLR4 in human fetal colon. Elevated IL-6 levels in immature colon after lipopolysaccharide were attenuated by $\mathrm{HC}$ in human and mouse.

CONCLUSION: Expression, localization, and signaling of TLR4 in colonic epithelium may be developmentally regulated. $\mathrm{HC}$ may accelerate the TLR developmental pathway change to an adult type, which may account for its impact on TLR4 signaling.

$\mathbf{N}$ ecrotizing enterocolitis (NEC) is the leading cause of death from gastrointestinal disease in the preterm infant (1). Up to 40 percent of afflicted premature infants require intestinal resection with a mortality rate of almost 50 percent and a significant subsequent morbidity (e.g., short bowel syndrome, etc) (2). The approach to management of the infant with NEC has not changed in the past $30 \mathrm{y}$ and the outcome is generally as poor today as it was three decades ago (3). These dismal results in current therapy for NEC highlight the urgent need for a better understanding of its pathogenesis and the importance of establishing novel, new therapies.

It has been suggested that an abnormal response by the premature infant to colonizing intestinal microbiota may contribute to the susceptibility of developing NEC. The incidence and mortality of NEC is highest in premature infants $(1,4,5)$ implicating gut immaturity as an additional risk factor. Intestinal maturation is affected by multiple factors such as intrinsic timing, exposure to trophic factors and cytokines in amniotic fluid, and the initial interaction with colonizing microbes $(6,7)$. For example, amniotic fluid and breast milk contain hydrocortisone (HC) that interacts with the gut during the perinatal period to stimulate a rapid transition to an adult enterocyte phenotype as reported with the induction of sucrose and galactosyltransferase and enterocyte plasma membrane maturation in previous studies, $(6,8,9)$ which may attenuate the expression of the disease.

NEC is characterized by a severe inflammation and necrosis of the intestine. Recent evidence has suggested that the nature of the Toll-like receptor 4 (TLR4) expressions within epithelium may contribute to the inflammatory response to enteric bacteria resulting in the development of NEC $(3,10)$. The function of TLR 4 signaling is determined, in part, by the cell in which it is expressed, by its selective use of signal transduction and by its cellular location and trafficking capacity (11-15). Although NEC can cause damage throughout the gut, it primarily evokes inflammation and necrosis in the distal small intestine and colon $(4,5)$. Unfortunately, the cellular distribution and trafficking of TLR4 in colonic cells is not well understood. Accordingly, in this study, we determined the location and degree of expression of TLR4 in immature human and mouse colonocytes and investigated whether a trophic hormone (HC) could affect its distribution and response.

\section{RESULTS}

TLR4 Expression in Human Fetal Colonic Epithelium

To investigate TLR4 expression in developing human colonic epithelium, we localized and quantitated the receptor at gestational ages 10 (Figure 1a), 16 (Figure 1b) and $21 \mathrm{wk}$ (Figure 1c) and at 4 mo postpartum (considered mature tissue) (Figure 1d) by immunofluorescence confocal microscopy. TLR4 was expressed on the apical surface, within the cytoplasm, at the basal cellular level of fetal colonic epithelium and in the lamina propria from 10 to $21 \mathrm{wk}$. At 4 mo postpartum, human colonic

'Department of Pediatrics, Mucosal Immunology and Biology Research Center, Massachusetts General Hospital for Children, Boston, Massachusetts; ${ }^{2}$ Section of Neonatology, Department of Pediatrics and Medicine, The University of Chicago, Chicago, Illinois. Correspondence: W. Allan Walker (wwalker@partners.org)

Received 5 June 2014; accepted 3 October 2014; advance online publication 14 January 2015. doi:10.1038/pr.2014.207 
a

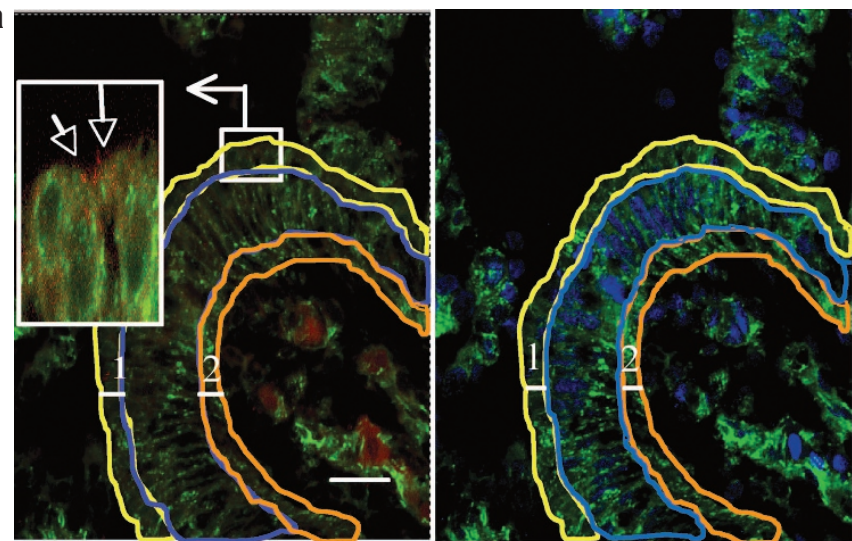

C

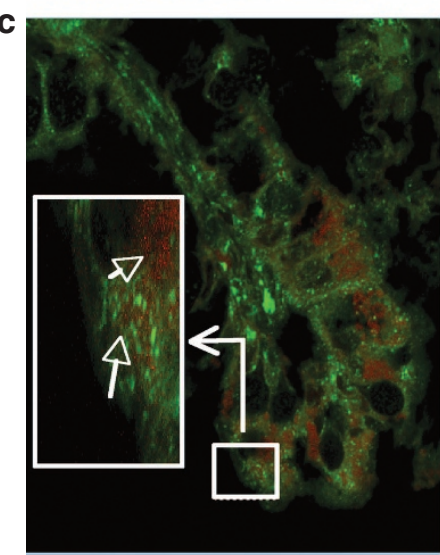

e

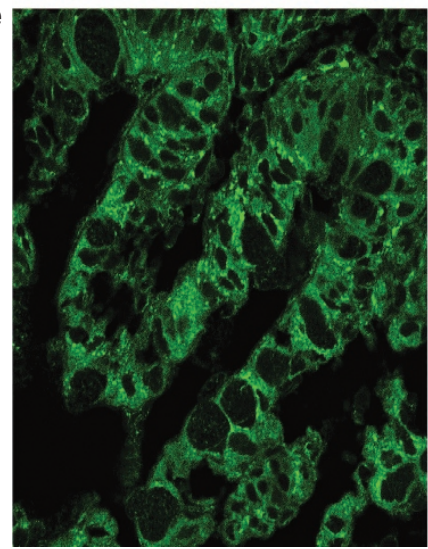

b
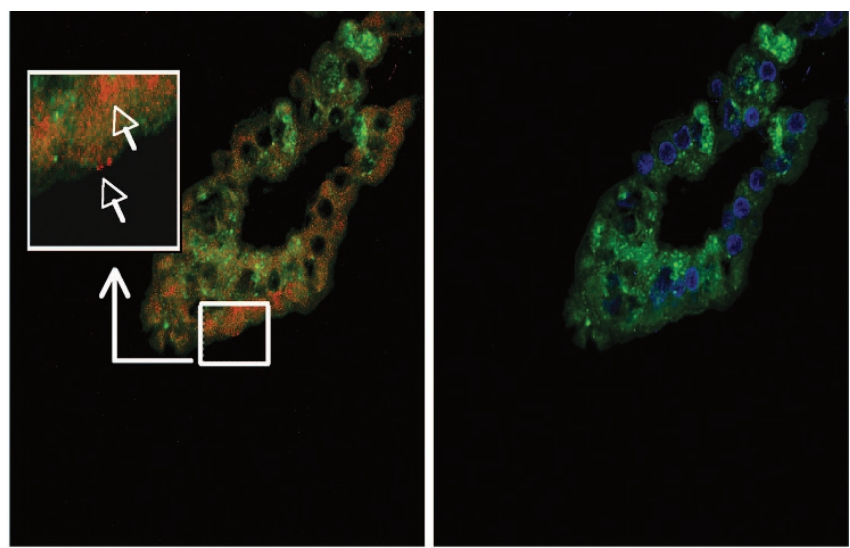

d

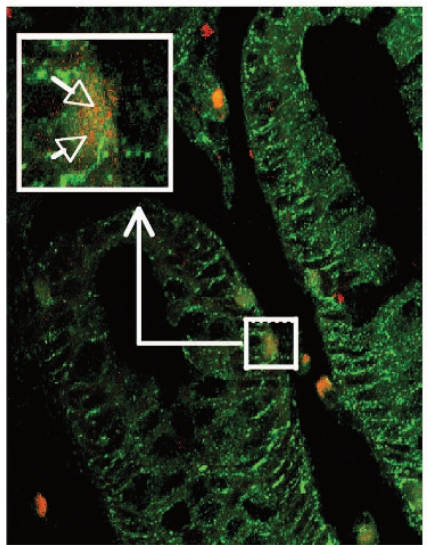

f

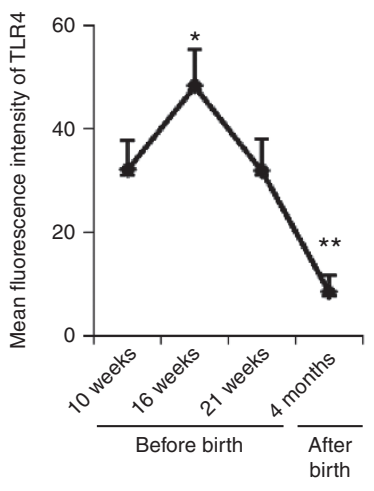

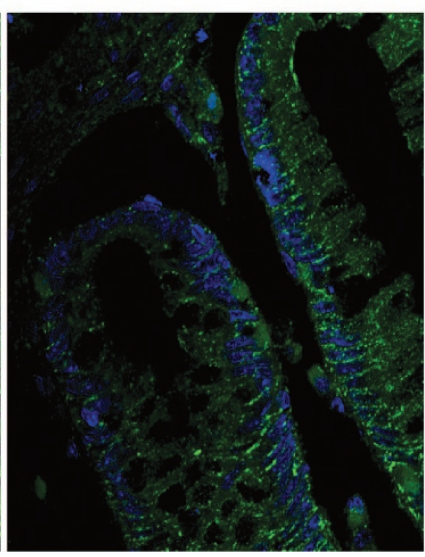

g

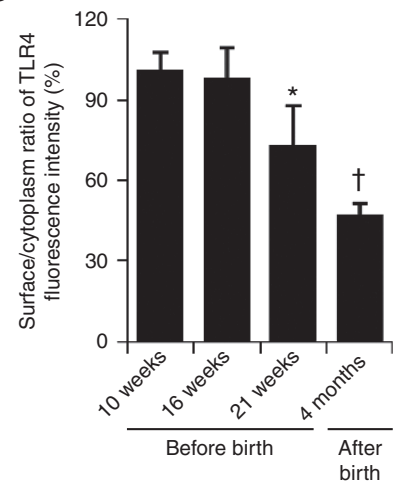

Figure 1. Location and quantity of Toll-like receptor 4 (TLR4) expression in human colonic epithelium from 10 wk gestation to 4 mo postpartum.

Confocal microscopy image (a-e) left pane: overlayer of human colon tissues stained with a phycoerythrin (PE) labeled anti-human TLR4 antibody (red) and a fluorescein isothiocyanate (FITC) labeled anti-phospholipid antibody (green) (as a cell membrane marker); right pane: overlayer of phospholipidFITC and DRAQ5(blue) (as a cell nuclear marker). Magnification: $\times 1,000$; scale bar: $-20 \mu \mathrm{m}$. (a) An area classification of colonic epithelium in a 10-wk human colon. The thickness of the surface (line 1) and basal membrane (line 2) both are $3.75 \mu \mathrm{m}$. Surface area is surrounded by a yellow line; cytoplasm area is surrounded by a blue line; and basal area was surrounded by a dark yellow line. (b) TLR4 expression at gestational age 16 wk, (c) 21 wk, and (d) 4 mo after birth. (e) Negative control for anti-human TLR4 antibody in a human fetal 16-wk colonic section. (f) The average mean fluorescence intensity of TLR4 expression within the whole epithelial area $(n=3-4)$ for each group, error bars represent SD, compared to a 10-wk gestational age group $(* P<0.05$, $\left.{ }^{* *} P<0.01\right)$. (g) Histogram of surface to cytoplasm ratio of TLR4 fluorescence intensity in colonic sections $(n=3-4)$ for each group, error bars represent SD, compared to a 10-wk gestational age group $\left(* P<0.05,{ }^{+} P<0.001\right)$.

TLR4 was scattered in crypt epithelial cells, lamina propria (Figure 1d) and occasionally detected on the apical surface and within the cytoplasm (data not shown). The quantity of TLR4 in fetal colonic epithelium increased to its highest level at gestational age 16-wk and then steadily decreased, reaching its lowest level at 4 mo postpartum (Figure 1f). The surface to cytoplasm ratio of TLR4 was highest at gestational age 10 and $16 \mathrm{wk}$, but decreased $27 \%$ by gestational age $21 \mathrm{wk}$ and an additional $26 \%$ by 4 mo postpartum (Figure $1 \mathrm{~g}$ ). These results suggest an increased expression of TLR4 in human fetal colonic epithelium that may be developmentally regulated, perhaps due to an intrinsic timing mechanism. A larger percentage of 


\section{Articles | Menget al.}
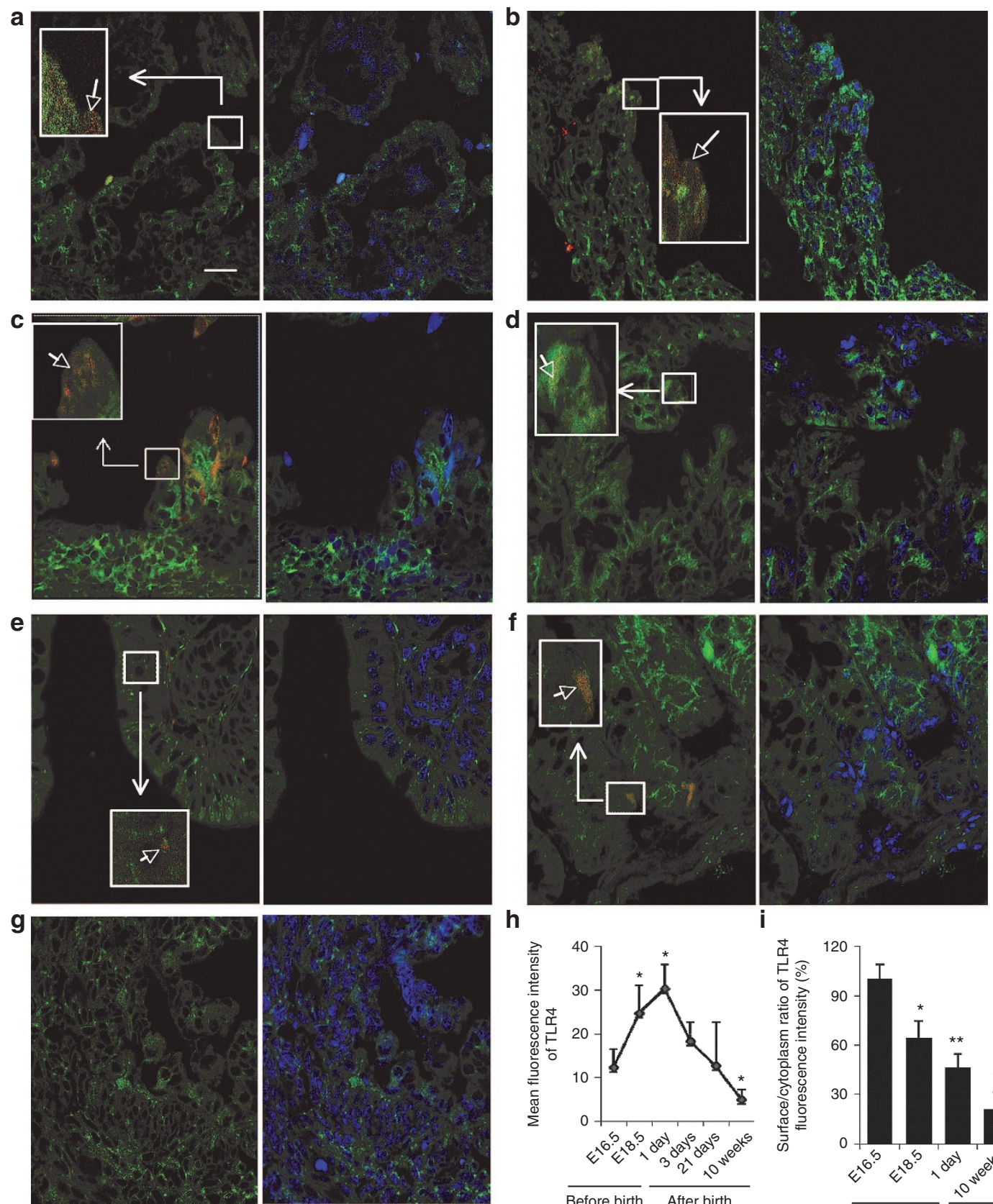

h
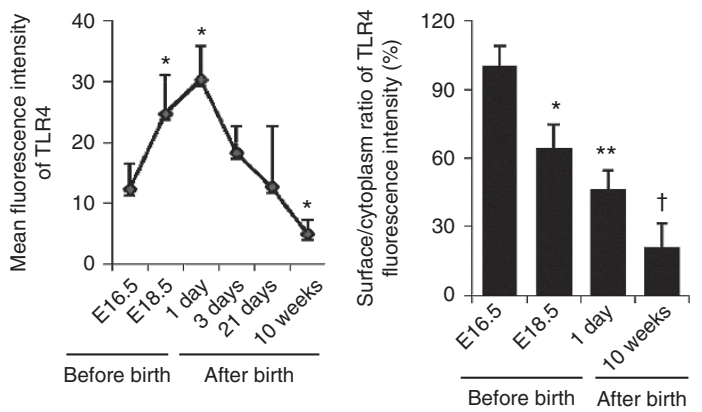

Figure 2. The ontogeny of Toll-like receptor 4 (TLR4) expression in mouse colonic epithelium during gestation and the postpartum period. Representative confocal image (a-g) left pane: overlayer of mouse colonic tissue stained with a phycoerythrin (PE)-labeled anti-mouse TLR4 antibody (red) and counter stained with fluorescein isothiocyanate (FITC) labeled anti-phospholipids antibody as a cell membrane marker (green). Right pane: overlayer of phospholipid-FITC and DRAQ5 (blue)(as a cell nuclear marker). The colonic epithelium classification uses the same measurement units as shown in Figure 1-a, but with $1.75 \mu \mathrm{m}$ as the thickness of surface and basal membranes. Magnification x 1000; scale bar-20 $\mu \mathrm{m}$. (a) Representative image of TLR4 expression E16.5, (b) E18.5 and, (c) postnatal days 1, (d) 3, (e) 21, and (f) 10 wk. (g) Negative control of an anti-mouse TLR4 in an E18.5 mouse fetal colonic section. (h) The average mean fluorescent intensity of TLR4 expression within the entire epithelial area ( $n=3-4$ for each group, error bars represent SD, ${ }^{*} P<0.05$ vs. E16.5). (i) Histogram of the surface to cytoplasm ratio of TLR4 fluorescent intensity in mouse colonic sections ( $n=3-4$ for each group, error bars represent $\mathrm{SD},{ }^{*} P<0.05,{ }^{* *} P<0.01,{ }^{+} P<0.001$ vs. E16.5).

TLR4 was present on the surface of enterocytes at earlier gestational ages.

\section{TLR4 Expression in Mouse Colonic Epithelium}

To study the ontogeny of TLR4 expression in mouse colon, we localized and quantitated TLR4 in C57BL/6J mice at embryonic day E 16.5 (Figure 2a), E 18.5 (Figure 2b), and postnatal days 1(Figure 2c), 3(Figure 2d), 21(Figure 2e) and at $10 \mathrm{wk}$ (Figure 2f) by immunofluorescent confocal microscopy. The quantity of TLR4 was high at E 16.5 and continued to increase until postnatal day 1 when it reached its peak and then decreased from postnatal day 3 to reach its lowest level at 
10 wk (Figure 2h). However, the surface to cytoplasm ratio of TLR4 was highest at E 16.5, and decreased at E18.5 through postnatal day 1 and continued to decrease until it reached the lowest level by $10 \mathrm{wk}$ after birth (Figure $2 \mathrm{i}$ ). These results suggest that the quantity and distribution of TLR4 also appears to be developmentally regulated in mouse colonic epithelium as evidenced by the observation showing a higher surface to cytoplasm distribution of TLR4 at the earlier gestational age. However, after birth presumably as the colon was exposed to colonizing microbiota, surface distribution of TLR4 rapidly decreased at the first day of the life and continued to decrease until $10 \mathrm{wk}$.

\section{HC Exposure Alters the TLR4 Response to LPS in Fetal Enterocytes}

To investigate if the trophic factor HC can alter the TLR4 signaling response to lipopolysaccharide (LPS) in immature colon, human fetal colon (FHC) cells were stimulated with or without $\mathrm{HC}$ at doses found in amniotic fluid for $5 \mathrm{~d}$ and then exposed to LPS (15 $\mu \mathrm{g} / \mathrm{ml})$. After $45 \mathrm{~min}$, supernatant interleukin (IL)-6 levels significantly increased in the control group and remained high at $6 \mathrm{~h}$ (Figure 3a). In contrast, LPS-stimulation failed to induce an IL-6 response in HC-treated (Figure 3b). We further determined the impact of maturation on LPS-TLR4 signaling by exposure of an adult human primary colonic epithelial cell line (NCM 460) to LPS. After $45 \mathrm{~min}$, supernatant IL-6 levels significantly decreased and only partially recovered at $6 \mathrm{~h}$ (Figure 3c). These results suggest that the trophic hormone HC can alter the LPS-induced TLR4 response from an immature to one comparable to a mature pattern.

\section{HC exposure to LPS in fetal mouse colon}

To investigate if $\mathrm{HC}$ can affect TLR4 signaling in immature mouse colon, pregnant $\mathrm{C} 57 \mathrm{BL} / 6 \mathrm{~J}$ mice were subcutaneously injected with $\mathrm{HC}$ once at a dose of $50 \mathrm{mg} / \mathrm{kg}$ on $\mathrm{E} 14.5$ or with the same volume of phosphate-buffered saline (PBS). A fetal colonic organ culture was established at E 18.5 and the colonic tissues exposed to LPS. In the PBS-treated control group, supernatant IL-6 levels increased significantly at $45 \mathrm{~min}$ and continued to increase at $6 \mathrm{~h}$ (Figure $4 \mathrm{a}$ ). However, in the HC pretreated group, IL-6 levels decreased significantly at $45 \mathrm{~min}$ and only recovered to baseline at $6 \mathrm{~h}$ (Figure $4 \mathrm{~b}$ ). To compare the LPS-induced TLR4 reaction in mature mouse colonic tissue, 10-wk postpartum $\mathrm{C} 57 \mathrm{BL} / 6 \mathrm{~J}$ colonic tissues were challenged with LPS in organ culture. After $45 \mathrm{~min}$, the supernatant IL-6 levels decreased significantly and returned
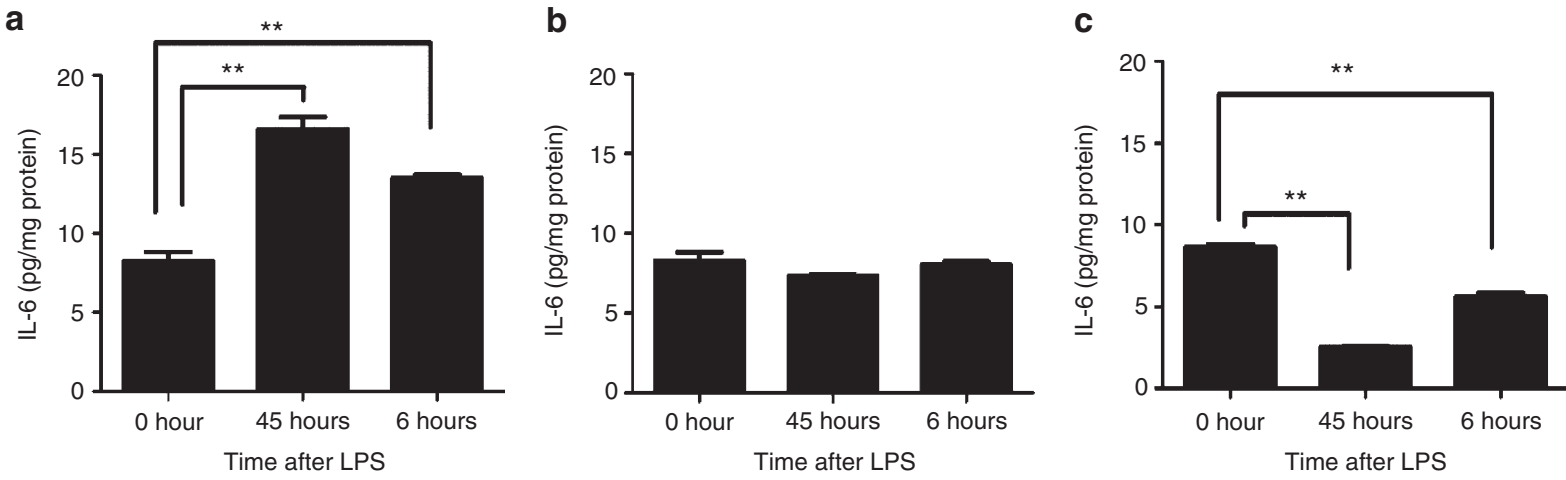

Figure 3. Hydrocortisone (HC) induces a shift in the Toll-like receptor 4 (TLR4) response to LPS in human fetal colonic epithelial cells. Human fetal colon cells (FHC) with or without HC pretreatment and adult human colonic epithelial cells (NCM 460) were stimulated with LPS for $45 \mathrm{~min}$ and for $6 \mathrm{~h}$ (a) a FHC cell line, (b) FHC pretreated with HC (1 $\mu \mathrm{mol} / \mathrm{l})$ for $5 \mathrm{~d}$, and (c) a NCM 460 cell line. The means and SD are from triplicate wells and are representative of three separate experiments, ${ }^{* *} P<0.01$ vs. 0 min.
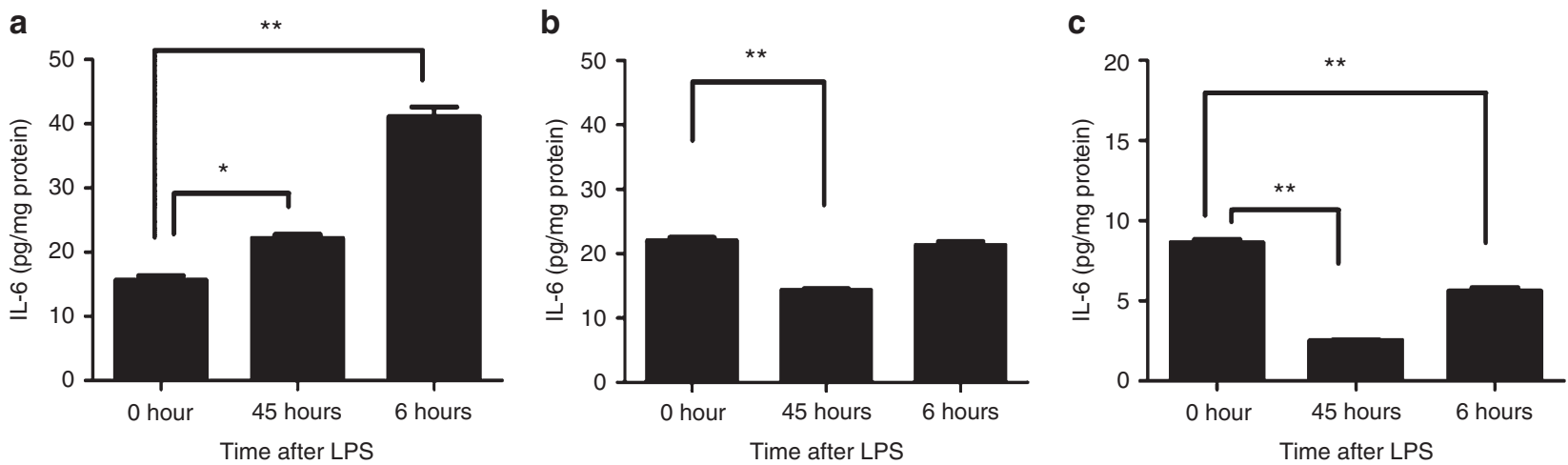

Figure 4. Hydrocortisone $(\mathrm{HC})$ induced a shift in the response of Toll-like receptor 4 (TLR4) to LPS in mouse fetal colonic organ culture. C57BL/6J fetal and adult mouse colonic tissues were incubated with LPS for $45 \mathrm{~min}$ and for $6 \mathrm{~h}$ and interleukin (IL)- 6 levels measured in the supernatant (a) E 18.5, (b) E18.5 from a mother treated with $\mathrm{HC}$, and (c) 12-wk adult mouse colonic tissues. The mean and SD are from triplicate wells, and are representative of three separate experiments, ${ }^{*} P<0.05,{ }^{* *} P<0.01 \mathrm{vs} .0 \mathrm{~min}$. 
to baseline levels at $6 \mathrm{~h}$ (Figure 4c). These results suggest that the TLR4response to LPS was different between immature and mature colon. Immature colon, expressing a greater quantity and more surface TLR4, had a greater IL-6 response to LPS stimulation than did mature colon, which expressed less total and more intracellular TLR4. Furthermore, pretreatment with $\mathrm{HC}$ resulted in the immature colon exhibiting a more mature response to LPS. These observations suggest that with intestinal maturation LPS-induced TLR4 signaling is reduced to a more mature response.

\section{HC Effect on the Surface to Cytoplasm TLR4 Ratio in Human Fetal Colonic Tissue}

To investigate if HC reduced LPS-induced TLR4 signaling by affecting the surface TLR4 expression, human fetal colonic tissues at 16 wk gestation $(n=3)$ were exposed to PBS (Figure $5 \mathrm{a}$ ) or HC (Figure 5b) in organ culture. After $20 \mathrm{~h}$, the surface to cytoplasm distribution of TLR4 was noted to be significantly decreased in HC-treated organ culture (Figure 5c). This observation suggests that the $\mathrm{HC}$ effect appears to reduce the surface to cytoplasm ratio of TLR4 and may account for the reduction of the LPS-induced TLR4 signaling in immature colonic epithelial cells exposed to trophic factors in utero.

\section{HC Effects on the Surface to Cytoplasm Ratio of TLR4 in Human Fetal Colonic Cells}

To provide further evidence that $\mathrm{HC}$ can reduce the surface to cytoplasm ratio of TLR4 in immature colon, FHC cells were exposed to PBS (Figure 6a) or HC (Figure 6b). After 5 d, the surface to cytoplasm ratio of TLR4 was noted to be significantly reduced in HC-treated cells (Figure 6c) suggesting that this response may account for its effect in reducing LPSinduced TLR4 signaling.

\section{DISCUSSION}

In this study, we have systematically examined TLR4 expression in fetal and neonatal human and mouse colonic epithelium. Our observations by morphologic quantitation and by a functional TLR4 response to LPS stimulation suggests that the TLR response to LPS stimulation appears to be developmentally regulated. Further support of this conclusion comes from the effect of a trophic hormone, HC (known to be present in both amniotic fluid and breast milk) on the surface to cytoplasmic ratio of TLR4 and a functional response of TLR4 to LPS stimulation in human fetal colonic tissue and a colonic cell line. In these experiments, exposure to $\mathrm{HC}$ resulted in maturation of TLR4 expression and function to that seen in the mature colon.

Since greater than $90 \%$ of NEC cases occur in premature infants weighing less than $1,500 \mathrm{~g}$ and involves severe inflammation and necrosis, principally of the distal small intestine and colon, it is generally assumed that a major risk factor is the interaction of colonizing bacteria with the immature intestine $(1,2)$. In studies from this laboratory, using intestinal models of fetal human intestine (16), we have reported that unlike mature enterocytes, the immature enterocyte responds excessively to
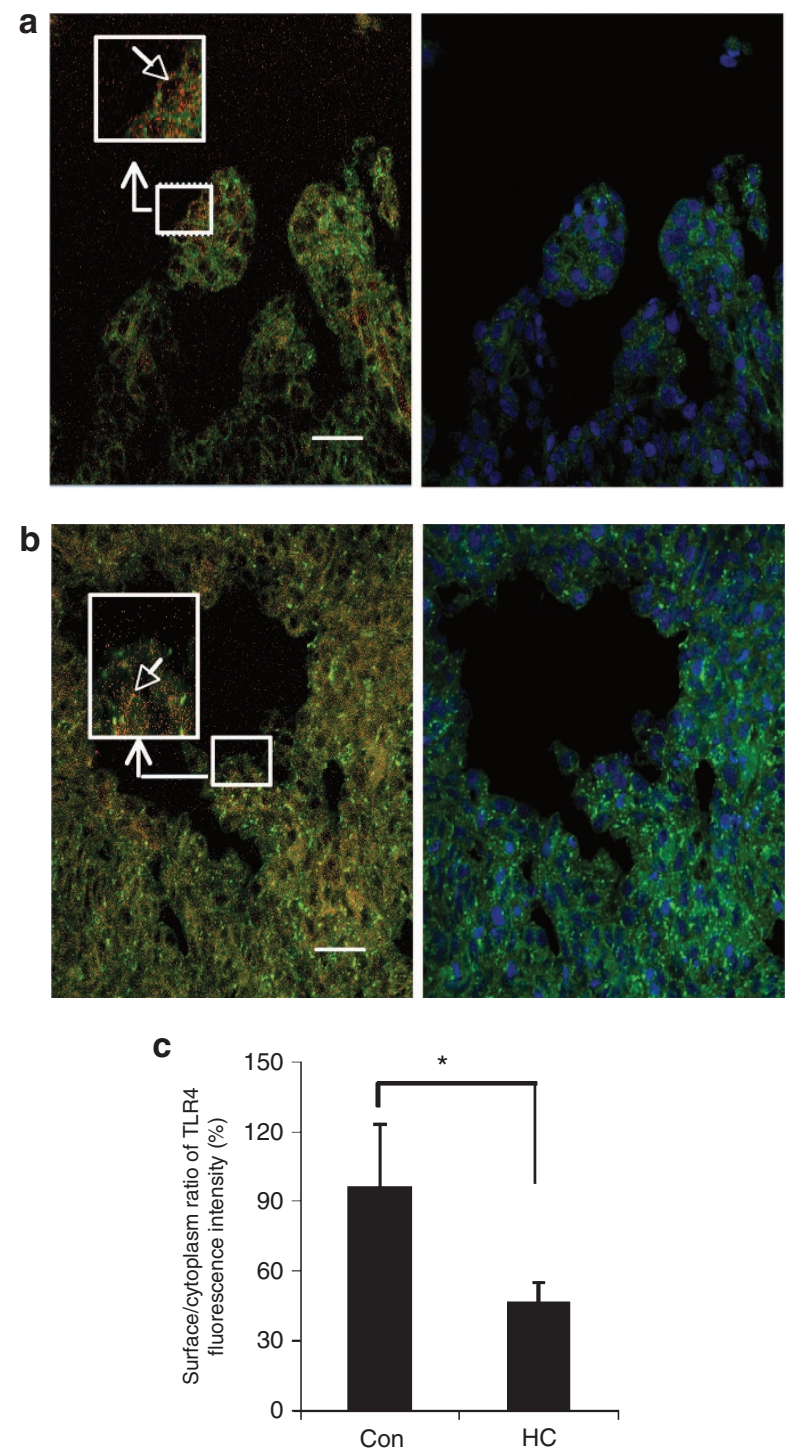

Figure 5. Hydrocortisone $(\mathrm{HC})$ reduces surface Toll-like receptor 4 (TLR4) expression in human fetal colonic epithelium. Human 16-wk fetal colonic tissues incubated for $2 \mathrm{~h}$ and then stimulated with $\mathrm{HC}$ or not for $20 \mathrm{~h}$. TLR4 expression was detected by the methods described. Original magnification: $\times 1000$; scale bar: $-20 \mu \mathrm{m}$. (a) TLR4 expression in control colonic sections. (b) HC pretreated colonic sections. (c) Histogram of the surface to cytoplasm ratio of TLR4 fluorescent intensity in control and $\mathrm{HC}$ pretreated colonic sections. The results represent the mean $\pm S D, n=3,{ }^{*} P<0.05$ vs. control group.

an exogenous (LPS) and endogenous (IL-1 $\beta$ ) stimulus $(17,18)$. More recently, we have reported that an immature expression of innate immune response genes may contribute to this excessive inflammatory response (19). As part of these studies, we have reported an increased expression of TLR4 in immature human fetal intestine. This study was designed to determine the developmental role of TLR4 expression and its response to LPS stimulation in human and mouse colonocytes. In a previous publication, we have reported for the first time that TLR4 was expressed on the basal lateral surface of a human primary fetal small intestinal cell line (H4 cells) and transcription was upregulated by inflammation (14). 

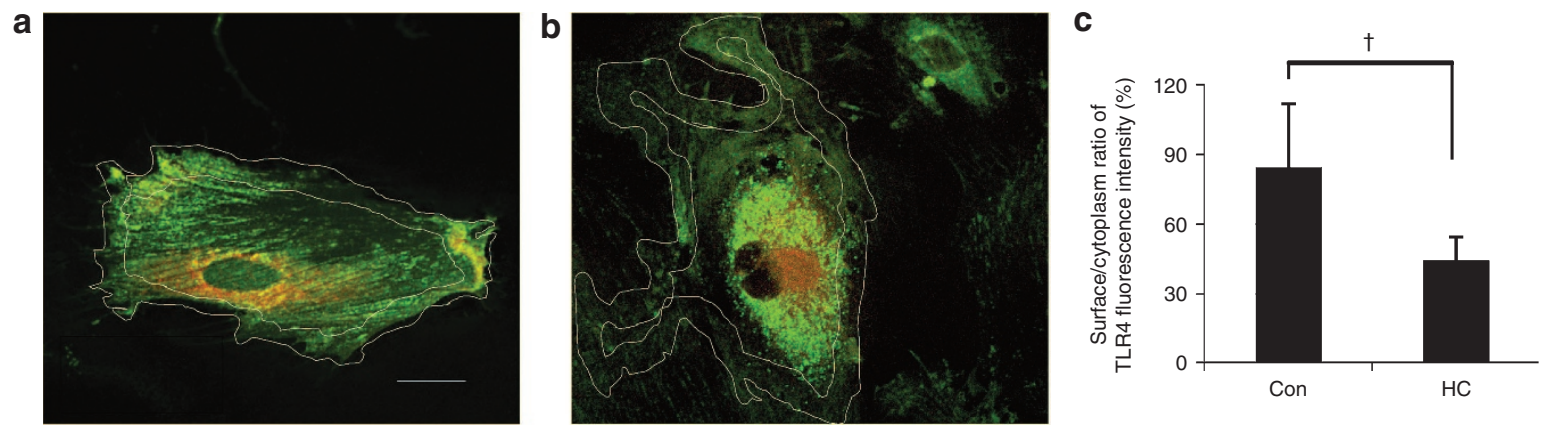

Figure 6. Hydrocortisone $(\mathrm{HC})$ reduces surface to cytoplasm ratio of Toll-like receptor 4 (TLR4) in fetal human colonic epithelial cells. Original magnification: $\times 1,000$; scale bar: $-20 \mu \mathrm{m}$ measured as previously described. (a) Control human fetal colon (FHC) cells. (b) HC pretreated FHC cells. (c) Histogram of the surface to cytoplasm ratio of TLR4 fluorescence intensity in control and HC pretreated FHC cells; results represent a mean $\pm \mathrm{SD}, n=10,{ }^{\dagger} P<0.001$ vs. control group.

Since that observation was published, other investigators have provided evidence implicating TLR4 in the pathogenesis of NEC. The Hackam group has reported that the expression of TLR4 is significantly greater in the premature mouse and human small intestine compared with their full-term counterpart and the expression of TLR4 is significantly elevated under conditions that are particularly relevant to the pathogenesis of NEC, namely the presence of hypoxia and exogenous bacteria expression of LPS $(15,20-22)$. In premature infants, TLR4 signaling within the small intestinal epithelium has been shown to regulate apoptosis, proliferation, and migration of enterocytes, the differentiation of goblet cells, and to reduce microcirculatory perfusion conditions, which collectively contribute to the development of NEC (3,12-17,19-23). Furthermore, the Caplan Research Group has shown that a TLR4 knockout mouse model cannot develop experimental NEC (24) suggesting a prominent role for this receptor and its signaling molecules in the pathogenesis of this disease. Despite these observations, the expression of TLR4 in developing colon has not been extensively studied. Accordingly, in this study, we have shown that fetal and early neonatal expression of TLR4 is much higher than in mature intestine. Furthermore, the earlier fetal colonic specimens have a higher surface to cytoplasmic ratio. We believe that this developmental expression of TLR4 in colonic cells likely contributes to the increased IL-6 response to LPS stimulation between immature and mature colon. Since the intrauterine environment is free of bacteria, the increased surface expression of this receptor may serve another function, e.g., as a developmental regulator in a manner similar to that which exists in the Drosophila.Toll was first discovered in Drosophila as a gene that controlled the dorsal-ventral axis of the developing embryo. Subsequently, TLR4 in the more mature Drosophila was noted to have an innate immune function. However, the functional significance of TLR4 other than for innate immunity in human intestine remains largely unknown (25). It is possible that TLR4 in human fetal intestine may have another function.

We know that the gastrointestinal tract in the extrauterine environment downregulates the transcription of TLR4 and the receptor is internalized to minimize unnecessary inflammation $(12,25)$. To prepare for full-term delivery, the fetus in the later stages of gestation is exposed to trophic factors in amniotic fluid, which cause maturation of the intestine. Previous observations $(6,8,9,26)$ suggest that $\mathrm{HC}$ affects intestinal maturation at multiple levels. Thus, we hypothesized that HC may play a role in colonic TLR4 expression. To address this hypothesis, we treated human fetal colon tissues with $\mathrm{HC}$ at gestational age 16 wk leading to the reduction of the TLR4 surface to cytoplasm ratio. A similar result was observed in a fetal human colonic epithelial cell line (FHC). These observations suggest that $\mathrm{HC}$ affects the regulation of TLR4 expression causing the immature colon to express a mature colonocyte phenotype.

It has been suggested that TLR4 location and cellular trafficking affects its function (27-29). TLR4 engages two distinct adaptor proteins: MyD88 which is recruited by TIRAP and elicits the production of proinflammatory cytokines and TRIF, which is recruited by the adaptor TRAM and activates the production of type 1 interferon as well as proinflammatory cytokines. Kagan et al. (13) have shown that TLR4 signals through TIRAP-MyD88 and TRAM-TRIF sequentially rather than simultaneously. Their data indicate that endocytosis of TLR4 terminates the initial phase of MyD88-dependent signaling and heralds the start of a second phase of TRIF-dependent signal transduction from TLR4 molecules located in endosome activated IRF3 for production of type 1 interferon (11-13). These reports suggest that the TLR4 activity is closely related to its location. Based on the difference of regional and spatial localization of TLR4 in immature and mature colon, we compared the proinflammatory response of TLR4 in human and mouse colon and found that with both LPS induced IL-6 induction was only observed in the immature colon which expressed high levels of TLR4 and more surface expression. In addition, IL-6 induction can be inhibited by pretreatment with $\mathrm{HC}$ which alters TLR4 expression from an immature to a mature pattern by reducing the surface to cytoplasm ratio. Our results suggest that the quantity, location of TLR4, and maturation effector HC are important for TLR4 signaling function in the immature colon.

Furthermore, in mouse colon, although the quantity of TLR4 continued to be high until the first day after birth, the surface to cytoplasm ratio of TLR4 was decreased. This result suggests that colonizing microbiota may in part regulate the 
distribution of TLR4 immediately after birth as has been previously suggested $(3,29)$. Although it is inappropriate to obtain the colonic tissue from infants at day 1 after birth, our murine model observations might be extrapolated to suggest what happens in humans.

In these experiments, TLR4 expression and its proinflammatory response to LPS may be influenced by fetal age, exposure to trophic amniotic factors, and early neonatal colonization. However, NEC is complex and may be caused by multiple additional factors that affect intestinal injury and repair. For example, in mature cells, TLR4 and an intracellular receptor TLR9 interact to affect proliferation and repair of tissue damage (3). Why the relationship does not exist in premature infants with its effect favoring inflammation must be determined in future studies.

In summary, the quantity and location of TLR4 in colonic epithelium appears to be developmentally regulated by a combination of genetic preprogramming, trophic factors and luminal microbiota, which in turn affect TLR4 function in the developing colon. This study for the first time provides insight into TLR4 expression in developing colon and may contribute to a better understanding of TLR4-specific contributions to NEC development and possibly provide a new TLR4-signaling specific therapeutic approach to preventing NEC.

\section{METHODS}

\section{Human Intestinal Tissue}

All specimens were collected with informed consent approved by the Human Studies Committee at the Massachusetts General Hospital (protocol \# 1999-P-003833). Human fetal colonic tissues were obtained from prostaglandin/saline-induced aborted fetuses at gestational ages of 10 , 16 , and $21 \mathrm{wk}(n=3-4$ per age group). Surgically resected marginal colonic tissues $(n=3)$ were obtained from patients undergoing intestinal resection for clinical indications. Tissues were maintained in 1066 media (Life Technologies, Rockville, MD) containing $100 \mathrm{U} / \mathrm{ml}$ penicillin and $100 \mu \mathrm{g} / \mathrm{ml}$ streptomycin (17). The fetal large intestine was identified as intestine between the appendix and anus. Tissues were washed with cold PBS at $4{ }^{\circ} \mathrm{C}$, fixed in $4 \%$ paraformaldehyde at $4{ }^{\circ} \mathrm{C}$ overnight, then washed with PBS containing 30\% sucrose, balanced in the same solution at $4{ }^{\circ} \mathrm{C}$ overnight, and embedded in optimal cutting temperature compound (Sakura Finetek USA, Torrance, CA). Frozen sections $(5-\mu \mathrm{m}$ thick) were kept at $-20^{\circ} \mathrm{C}$ for later use.

\section{Human Colonic Organ Culture}

Sixteen-week gestational aged human colonic tissues were collected $(n=3)$, cut into $3-\mathrm{mm}$ pieces and cultured in BD-Falcon Tissue Culture Plates (Becton, Dickinson and Company, Franklin Lakes, NJ) with Opti-MEM media (Life Technologies, Grand Island, NY) supplemented with $10 \mathrm{mmol} / \mathrm{l}$ 4-(2-hydroxyethyl)-1piperazineethanesulfonic acid (HEPES), $2.5 \mathrm{mmol} / \mathrm{lglutamine}, 20 \mathrm{ng} /$ $\mathrm{ml}$ human epidermal growth factor, $10 \mu \mathrm{g} / \mathrm{ml}$ insulin, $4 \%$ fetal bovine serum, $100 \mathrm{U} / \mathrm{ml}$ penicillin and $100 \mu \mathrm{g} / \mathrm{ml}$ streptomycin, $2 \mathrm{mmol} / \mathrm{l}$ GlutaMAX-I at $37^{\circ} \mathrm{C}$ with $95 \% \mathrm{O}_{2}, 5 \% \mathrm{CO} 2(16)$ for $2 \mathrm{~h}$, and then exposed to HC $(1 \mu \mathrm{mol} / \mathrm{l})$ or PBS for $20 \mathrm{~h}$. Fixation and frozen sections were prepared as described above.

\section{Animals}

C57BL/6J mice were purchased from Jackson Laboratory (Bar Harbor, ME). All mice were bred and housed in a specific pathogenfree facility. Animals were given water and standard laboratory chow ad libitum. Timed pregnant mice were set up by pairing 10-12-wkold female mice with proven breeder males just prior to the end of the daily light cycle. The following morning, each female was examined for the presence of an ejaculatory plug in the vagina. When noted, the female was placed in a dated cage and considered pregnant, embryonic day (E) 0.5. Pups were delivered by caesarean delivery between day E16.5 and 18.5. Colonic tissues were collected for experiments. In addition viable mice were sacrificed on day $1,3,21$, and $10 \mathrm{wk}$ after birth and colon tissues collected. Animal procedures were approved by the Massachusetts General Hospital Subcommittee on Research Animal Care and Use committee (A3596-01).

\section{Prenatal HC Treatment}

Pregnant C57BL/6J mice were injected subcutaneously with a single dose of HC $(50 \mathrm{mg} / \mathrm{kg}$ body weight, $n=3)(6)$ or an equal volume of saline $(n=3)$ at day E14.5 and the fetal colonic tissues obtained at day E18.5 for experimental use.

\section{Mouse Colonic Organ Culture}

Mouse fetal colonic tissues were obtained at E 18.5 with or without $\mathrm{HC}$ treatment during pregnancy, and 10 -wk-old adult mice colonic tissues were cut into $3-\mathrm{mm}$ pieces and cultured under conditions described in the human colonic organ culture section. After $2 \mathrm{~h}$ at $37^{\circ} \mathrm{C}$, tissues were stimulated with ultra purified LPS 0111:B4 from Escherichia coli (List Biological Laboratories, Campbell, CA) or PBS for $45 \mathrm{~min}$ and $6 \mathrm{~h}$. Supernatants were collected and stored at $-20{ }^{\circ} \mathrm{C}$ for enzyme-linked immunosorbent assay (ELISA) analysis.

\section{Cell Cultures}

Normal nonimmortalized epithelial FHC were purchased from American Type Culture Collection (Manassas, VA) and maintained in the prescribed media. Briefly, 90\% Dulbecco's modified Eagle medium: nutrient mixture F-12 media (American Type Culture Collection) and 10\% fetal bovine serum (Mediatech, Manassa, VA), supplemented with $25 \mathrm{mmol} / \mathrm{l}$ HEPES (Life Technologies); $10 \mathrm{ng} /$ $\mathrm{ml}$ cholera toxin (Sigma Aldrich, St Louis, MO); $0.005 \mathrm{mg} / \mathrm{ml} \mathrm{insu-}$ lin (Eli Lilly and Company, Indianapolis, IN); $0.005 \mathrm{mg} / \mathrm{ml}$ transferrin and $100 \mathrm{ng} / \mathrm{ml}$ (equal $0.2 \mu \mathrm{mol} / \mathrm{l}$ ) HC (Sigma Aldrich); $100 \mathrm{U} / \mathrm{ml}$ penicillin and $100 \mu \mathrm{g} / \mathrm{ml}$ streptomycin (Life Technologies). Cells were maintained at $37^{\circ} \mathrm{C}$ in $5 \% \mathrm{CO}_{2}, 95 \% \mathrm{O}_{2}$ in a humidified incubator. Human adult NCM460 colonocytes derived from normal colon were provided by INCELL (San Antonio, TX) and cultured in M3:Base A (M3A) media (INCELL), supplemented with $10 \%$ fetal bovine serum, $100 \mathrm{U} / \mathrm{ml}$ penicillin, and $100 \mu \mathrm{g} / \mathrm{ml}$ streptomycin. The cells were cultured at $37^{\circ} \mathrm{C}$ in $5 \% \mathrm{CO}_{2}$, and $95 \% \mathrm{O}_{2}$ in a humidified incubator.

\section{LPS and HC Cellular Exposure}

FHC and NCM 460 cells were cultured in 24-well BD-Falcon tissue culture plates (Becton, Dickinson and Company). FHC cells, at $70 \%$ confluence, were treated with or without $\mathrm{HC}(1 \mu \mathrm{mol} / \mathrm{l})$ for $5 \mathrm{~d}$. The cells were then treated with or without $15 \mu \mathrm{g} / \mathrm{ml}$ ultrapurified LPS 0111:B4 from E. coli for $45 \mathrm{~min}$ and $6 \mathrm{~h}$. Supernatants were collected and stored at $-20{ }^{\circ} \mathrm{C}$ for ELISA analysis. NCM 460 cells at $90 \%$ confluence were also treated with or without LPS $(15 \mu \mathrm{g} / \mathrm{ml})$ for $45 \mathrm{~min}$ and $6 \mathrm{~h}$ and supernatants were then collected and stored at $-20^{\circ} \mathrm{C}$ for ELISA analysis.

\section{Immunofluorescent Staining}

The human or mouse colonic frozen sections were washed with PBS and blocked with 3\% bovine serum albumin in PBS for $1 \mathrm{~h}$. They were then incubated with Phycoerythrin (PE)-conjugated anti-human or mouse TLR4 antibody (1:20) (both eBioscience, San Diego, CA) or with mouse IgG2a kappa isotype antibody $(1: 20)$ as a negative con-

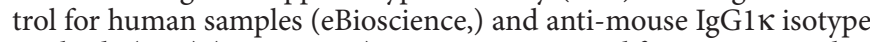
antibody (1:20) (eBioscience) as a negative control for mouse samples, all in $1 \%$ bovine serum albumin containing $0.3 \%$ saponin at $37^{\circ} \mathrm{C}$ for $1 \mathrm{~h}$, then washed three times with PBS and counter stained with fluorescein isothiocyanate-labeled anti-phospholipid antibody (1:400) as a cell membrane marker, in $1 \%$ bovine serum albumin containing $0.3 \%$ saponin (Life Technologies) at room temperature for $1 \mathrm{~h}$. After three times washing with PBS, they were overstained with 1,5-bis $\{[\alpha$-(di-methylamino) ethyl $]$ amino $\}$-4, 8-dihydroxyanthracene-9, 10-dione (DRAQ5) (1:1,000) (Life Technologies) for $20 \mathrm{~min}$ at room temperature for nuclear visualization. Specimens were then washed three times with PBS, mounted with ProLong Antifade Reagent (Life Technologies) and analyzed with a fluorescent Leica confocal microscope. FHC cells cultured on glass coverslips in six-well tissue culture 
plates at $70 \%$ confluence were treated with or without $\mathrm{HC}(1 \mu \mathrm{mol} / \mathrm{l})$ for $5 \mathrm{~d}$, washed with PBS and fixed in $4 \%$ paraformaldehyde for $15 \mathrm{~min}$ at room temperature, washed with PBS, then using blocking and staining steps as described.

\section{Analysis of TLR4 Quantity and Location}

Total TLR4 (represented by a mean TLR4 epithelial fluorescent intensity) and the surface to cytoplasm ratio of TLR4 were measured by confocal micro-photo analysis with Image J (fiji-win64) software. The scale set up for measurement was based on specific scanning conditions, e.g., distance in pixels. Color channels were used as a measure of fluorescent intensity of TLR4 (PE-TLR4) in red and fluorescein isothiocyanate-labeled antiphospholipid in green as a measure of the cell membranes. Phospholipid staining was used to measure the thickness of cell membrane because the main component of the cell membrane lipid bilayer is phospholipid. Figure 1a depicts in color the thickness of the cell, the cell membrane (yellow line), the basal area (dark yellow line), and the cytoplasm, e.g., the area between cell membrane and basal area markers. The whole colonic epithelial area represents the sum of surface, cytoplasm, and basal areas. Total TLR4 was measured by determining fluorescent intensity of the whole epithelial area minus background from three to four images (one image/ sample) and the surface to cytoplasmic TLR4 ratio was measured by (fluorescent intensity of the surface area minus background)/(cytoplasm area minus background $) \times 100(n=3-4)$. These methods were also used in mouse colon TLR4 quantitation and localization.

\section{ELISA}

Levels of IL-6 were measured in culture supernatants using ELISA kits ( $\mathrm{R} \& \mathrm{D}$ system, Minneapolis, $\mathrm{MN}$ ) according to the manufacturer's instructions. IL- 6 was quantified in each supernatant in triplicate. Colorimetric results were read at a wavelength of $450 \mathrm{~nm}$. Values were normalized to total protein in cells or organ cultures. Protein was determined by the bicinchoninic acid protein assay (Pierce, Rockford, IL) modified for 96-well microtiter plates according to the manufacturer's protocol.

\section{Statistical Analysis of Data}

Results were expressed as the mean \pm SE and were analyzed by a two-way ANOVA and with a post-hoc two-tailed unpaired $t$-test. Differences of a $P$ value $<0.05$ were considered significant $\left({ }^{\star} P<0.05\right.$, $\left.{ }^{* *} P<0.01,{ }^{\dagger} P<0.001\right)$.

\section{ACKNOWLEDGMENTS}

D.M.: Contributed to experimental design, experiments, and manuscript preparation; W.Z.: helped with experiments and sample collection; H.S.: made suggestions for experimental design, and provided technical assistance; L.L.: made suggestions for experimental design and technical approach; V.W.: contributed to experiments; V.X.: contributed to morphologic studies; W.A.W.: made substantial contribution to concept and design and manuscript preparation. We also express our gratitude to the coordinating medical and research staff at Mucosal Immunology and Biology Research Center, Massachusetts General Hospital for Children, Boston, MA, and special thanks to Bobby Cherayil for technical support; Suzzette McCarron for manuscript organization; Meiqian Weng and Kriston Ganguli for coordination and Maureen Garron for administrative support. We also owe special thanks to Kathleen Sirois at Brigham and Women's Hospital, Boston, $\mathrm{MA}$, for sample collection.

\section{STATEMENT OF FINANCIAL SUPPORT}

This work was supported by grants from National Institutes of Health (Bethesda, MD): P01DK033506 and P30 DK040561, RO1-HD059126, RO1HD12437 (to W.A.W.) and R01 DK08427 (to H.S.).

Disclosure: The authors have no competing interests.

\section{REFERENCES}

1. Neu J, Walker WA. Necrotizing enterocolitis. N Engl J Med 2011;364: 255-64.

2. Grave GD, Nelson SA, Walker WA, et al. New therapies and preventive approaches for necrotizing enterocolitis: report of a research planning workshop. Pediatr Res 2007;62:510-4.
3. Afrazi A, Sodhi CP, Richardson W, et al. New insights into the pathogenesis and treatment of necrotizing enterocolitis: Toll-like receptors and beyond. Pediatr Res 2011;69:183-8.

4. Kosloske AM. Epidemiology of necrotizing enterocolitis. Acta Paediatr Suppl 1994;396:2-7.

5. Beeby PJ, Jeffery H. Risk factors for necrotising enterocolitis: the influence of gestational age. Arch Dis Child 1992;67(4 Spec No):432-5.

6. Nanthakumar NN, Dai D, Meng D, Chaudry N, Newburg DS, Walker WA. Regulation of intestinal ontogeny: effect of glucocorticoids and luminal microbes on galactosyltransferase and trehalase induction in mice. Glycobiology 2005;15:221-32.

7. Hooper LV, Bry L, Falk PG, Gordon JI. Host-microbial symbiosis in the mammalian intestine: exploring an internal ecosystem. Bioessays 1998;20:336-43.

8. Nanthakumar NN, Young C, Ko JS, et al. Glucocorticoid responsiveness in developing human intestine: possible role in prevention of necrotizing enterocolitis. Am J Physiol Gastrointest Liver Physiol 2005;288: G85-92.

9. Lu L, Bao Y, Khan A, et al. Hydrocortisone modulates cholera toxin endocytosis by regulating immature enterocyte plasma membrane phospholipids. Gastroenterology 2008;135:185-193.e1.

10. Harju K, Ojaniemi M, Rounioja S, et al. Expression of toll-like receptor 4 and endotoxin responsiveness in mice during perinatal period. Pediatr Res 2005;57(5 Pt 1):644-8.

11. Chaturvedi A, Pierce SK. How location governs toll-like receptor signaling. Traffic 2009;10:621-8.

12. Watts C. Location, location, location: identifying the neighborhoods of LPS signaling. Nat Immunol 2008;9:343-5.

13. Kagan JC, Su T, Horng T, Chow A, Akira S, Medzhitov R. TRAM couples endocytosis of Toll-like receptor 4 to the induction of interferon-beta. Nat Immunol 2008;9:361-8.

14. Fusunyan RD, Nanthakumar NN, Baldeon ME, Walker WA. Evidence for an innate immune response in the immature human intestine: toll-like receptors on fetal enterocytes. Pediatr Res 2001;49:589-93.

15. Lu P, Sodhi CP, Hackam DJ. Toll-like receptor regulation of intestinal development and inflammation in the pathogenesis of necrotizing enterocolitis. Pathophysiology 2014;21:81-93.

16. Sanderson IR, Ezzell RM, Kedinger M, et al. Human fetal enterocytes in vitro: modulation of the phenotype by extracellular matrix. Proc Natl Acad Sci USA 1996;93:7717-22.

17. Nanthakumar NN, Fusunyan RD, Sanderson I, Walker WA. Inflammation in the developing human intestine: A possible pathophysiologic contribution to necrotizing enterocolitis. Proc Natl Acad Sci USA 2000;97:6043-8.

18. Claud EC, Lu L, Anton PM, Savidge T, Walker WA, Cherayil BJ. Developmentally regulated IkappaB expression in intestinal epithelium and susceptibility to flagellin-induced inflammation. Proc Natl Acad Sci USA 2004; 101:7404-8.

19. Nanthakumar N, Meng D, Goldstein AM, et al. The mechanism of excessive intestinal inflammation in necrotizing enterocolitis: an immature innate immune response. PLoS One 2011;6:e17776.

20. Gribar SC, Anand RJ, Sodhi CP, Hackam DJ. The role of epithelial Toll-like receptor signaling in the pathogenesis of intestinal inflammation. J Leukoc Biol 2008;83:493-8.

21. Hackam DJ, Afrazi A, Good M, Sodhi CP. Innate immune signaling in the pathogenesis of necrotizing enterocolitis. Clin Dev Immunol 2013;2013:475415.

22. Leaphart CL, Cavallo J, Gribar SC, et al. A critical role for TLR4 in the pathogenesis of necrotizing enterocolitis by modulating intestinal injury and repair. J Immunol 2007;179:4808-20.

23. Richardson WM, Sodhi CP, Russo A, et al. Nucleotide-binding oligomerization domain-2 inhibits toll-like receptor- 4 signaling in the intestinal epithelium. Gastroenterology 2010;139:904-17, 917.e1-6.

24. Jilling T, Simon D, Lu J, et al. The roles of bacteria and TLR4 in rat and murine models of necrotizing enterocolitis. J Immunol 2006;177:3273-82.

25. Abreu MT. Toll-like receptor signalling in the intestinal epithelium: how bacterial recognition shapes intestinal function. Nat Rev Immunol 2010;10:131-44. 


\section{Articles $\mid$ Mengetal.}

26. Biol MC, Martin A, Richard M, Louisot P. Developmental changes in intestinal glycosyl-transferase activities. Pediatr Res 1987;22:250-6.

27. Hornef MW, Frisan T, Vandewalle A, Normark S, Richter-Dahlfors A. Toll-like receptor 4 resides in the Golgi apparatus and colocalizes with internalized lipopolysaccharide in intestinal epithelial cells. J Exp Med 2002;195:559-70.
28. Zanoni I, Ostuni R, Marek LR, et al. CD14 controls the LPS-induced endocytosis of Toll-like receptor 4. Cell 2011;147:868-80.

29. Abreu MT, Vora P, Faure E, Thomas LS, Arnold ET, Arditi M. Decreased expression of Toll-like receptor- 4 and MD- 2 correlates with intestinal epithelial cell protection against dysregulated proinflammatory gene expression in response to bacterial lipopolysaccharide. J Immunol 2001;167:1609-16. 